\title{
Una mirada desde España: mensajes y medios de comunicación de los refugiados de Europa del Este
}

\author{
Matilde EIROA SAN FrANCISCO \\ Universidad Carlos III de Madrid \\ meiroa@hum.uc3m.es
}

Recibido: $15 / 03 / 2011$

Aceptado: 23/09/2011

\section{Resumen}

El presente texto se propone analizar los mensajes y los medios de comunicación editados por los refugiados políticos procedentes del Telón de Acero y por instituciones españolas en el periodo 1949-1969. Estos medios constituyen un capítulo singular de la comunicación en España, que ha de entenderse desde la correlación existente entre la producción informativa nacional y la internacional, puesto que se extendieron a lo largo de los países de destino, principalmente Europa y Estados Unidos. En el artículo estudiamos sus contenidos y nos preguntamos qué tipo de funciones tuvieron, cuál fue su conexión con otros medios de la diáspora anticomunista y el papel que desempeñaron entre dicho colectivo.

Palabras clave: Prensa anticomunista, refugiados políticos, Europa del Este, Franquismo.

\section{A Spanish outlook: media messages and refugees from Eastern Europe}

\begin{abstract}
This text aims to analyze the messages and the mass media produced by refugees from the Iron Curtain and Spanish institutions. These media are a unique chapter in the Spanish communication, which is understood from the existing correlation between national information production and the international, because the spread along several countries, mainly in Europe and United States. In the article we study the content and we wonder what kind of functions had, which connection had with another anticommunist Diaspora media and the role played between this collective.
\end{abstract}

Keywords: anticommunist newspaper, political refugees, Eastern Europe, Francoism.

\section{Referencia normalizada}

EIROA SAN FRANCISCO, Matilde (2011): "Una mirada desde España: mensajes y medios de comunicación de los refugiados de Europa del Este". Estudios sobre el mensaje periodístico. Vol. 17, núm. 2, págs.: 479-497. Madrid, Servicio de Publicaciones de la Universidad Complutense.

Sumario: 1. Introducción. 2. Fuentes y metodología. 3. El contexto histórico de la inmigración política centroeuropea. 4. La prensa del exilio polaco: el caso de Polonia. Revista Ilustrada. 5. La prensa del exilio rumano: Libertatea y Carpatti. 6. Los medios oficiales para combatir el comunismo internacional: Radio Nacional de España y la prensa especializada. 7. Conclusiones. 8. Referencias bibliográficas.

\section{Introducción}

Los estudios sobre la comunicación durante la dictadura franquista se hallan en un estado muy consolidado gracias a la multitud de investigaciones de carácter general y local que se han venido realizando desde hace tiempo. En la actualidad contamos con un conjunto importante de textos sobre su marco jurídico y legislativo, análisis generales y análisis pormenorizados de prensa local y especializada que ofrecen un panorama muy completo de dicha etapa, aunque todavía hace falta indagar sobre aspectos de la estructura mediática que sólo están esbozados (BARRERA, 1995; CHULIÁ, 1997; GARCía GALINDO, 2002).

Uno de los temas que requieren de una investigación sistematizada es el de los medios de comunicación de los extranjeros residentes en España. La producción acadé- 
mica sobre este aspecto es reducida, en parte debido a que su auge tuvo lugar en la década de 1980, y en parte por la idea extendida de que en los años del gobierno franquista apenas había foráneos en territorio nacional. Bajo el concepto de "prensa extranjera" encontramos los trabajos de L. LÓPEZ ROMERo (2009a y 2009b), J. A. GARCÍA GALINDO (1998) y P.A. SALVÀ TomÁs (2002), planteados desde una perspectiva de los medios como integradores sociales y desde su vinculación al turismo. En este artículo, sin embargo, presentamos una investigación sobre una categoría distinta a la anterior que se refiere a la producción periodística de refugiados procedentes de las democracias populares cuando se hizo efectiva la división del mundo en bloques.

Esta singularidad socio-comunicativa forma parte de una temática extendida en Europa entre los estudios culturales, conceptuada como "prensa de minorías", "prensa en la diáspora" o "prensa inmigrante". Judith R. Blau (1998: 13-24) ha justificado el uso del concepto "inmigrant press" para el caso de los medios impresos de las comunidades extranjeras residentes en New York entre 1820 y 1984, aunque a veces lo combina con el de "prensa étnica". Este término ha sido el preferido de especialistas como J.M. LACROIX (1998) o I. RigONI (2007), quienes han analizado los canales de comunicación de minorías culturales y lingüísticas asentadas en Canadá o Italia. En este texto se ha considerado más adecuado el concepto "prensa de los refugiados políticos" o "prensa de la diáspora", puesto que el objeto de estudio es una tipología mediática producida por los exiliados centro-europeos en lengua española, financiada por organizaciones internacionales -como la Cruz Roja-, o instituciones de dicho exilio multinacional asentadas en España. Ambos términos son más clarificadores que los de "prensa extranjera" -foráneos residentes sin más calificativos- o "prensa inmigrante" -cuya connotación económica puede dar lugar a equívocos-, sobre todo porque explicitan el componente político y el origen de la colectividad promotora de las mismas.

\section{Fuentes y metodología}

Esta investigación está planteada sobre la base de la metodología cualitativa y aplica tres de sus técnicas: la observación documental, la entrevista en profundidad y el análisis de contenido cualitativo (JENSEN y JANKOWSKI, 1993; BERGANZA, 2005; MARTíNEZ NiCOLÁs, 2008). En cuanto a la observación documental, se ha utilizado como plantilla la ficha hemerográfica concebida por Jacques Kayser y mejorada posteriormente con el propósito de diseñar una vía sistemática para la investigación de los medios escritos. La ficha facilita el análisis de los datos técnicos de la publicación, como el emisor, los años de vida, el formato, el espacio redaccional, las secciones, los géneros periodísticos, las fuentes, los redactores y una síntesis de los mensajes. Proporciona una información empírica que abre el camino para una interpretación de los datos a través del enfoque inductivo.

${ }^{1}$ En la European Communication Research Association (ECREA) hay una sección específica denominada "Diaspora, Migration and Media Section" y existe una amplia red social sobre medios de las minorías étnicas y emigrados, en: http://www.ourmedianetwork.org/wiki/bibliography:ams_theme:minorities (consultado el 7 de febrero de 2011) 
La utilización de la entrevista en profundidad tiene aquí tres finalidades: la primera, proporcionar información que no hemos localizado en los archivos documentales; la segunda, complementar ciertas lagunas informativas, y la tercera ratificar algunos aspectos aparecidos en dichas fuentes. Igualmente se ha aplicado la técnica del análisis de contenido cualitativo del cual hemos extraído las grandes líneas temáticas de las cabeceras analizadas. Finalmente se ha procedido a la síntesis de los contenidos de los legajos custodiados en el archivo del Ministerio de Asuntos Exteriores, la Fundación Nacional Francisco Franco, el archivo particular de Zoltán Rónai y la documentación sobre $R N E$ existente en el Archivo General de la Administración.

Los principales medios de comunicación de los refugiados fueron: 1) los editados por los polacos: Polonia. Revista ilustrada, Nosotros, El Comercio exterior de Polonia, El Comercio exterior polaco; 2) sobre Rumania: Libertatea, Boletín rumano, Carpatii, Límites, Estaciones y El Hecho; 3) Eslovaquia: Noticiero eslovaco. 4) publicaciones españolas sobre el conjunto multinacional centroeuropeo: Boletín de las Naciones Oprimidas por el Comunismo, Oriente, Oriente Europeo, Oriente cristiano, Re-unión, Unidad cristiana y, las emisiones en lenguas extranjeras de Radio Nacional de España. De esta relación se ha seleccionado una muestra representativa que permita ofrecer una explicación a este fenómeno integrada por: Polonia. Revista Ilustrada, Libertatea y Carpatii, cabeceras ilustrativas de los exiliados más activos social y políticamente: polacos y rumanos; el Boletín de las Naciones Oprimidas por el Comunismo, editado por el conjunto multinacional del este europeo; Oriente euro$p e o$, revista publicada por instituciones españolas; y las emisiones de $R N E$. Las razones que han llevado a excluir otras cabeceras han sido la escasa representatividad, la corta duración -caso de El Noticiero Eslovaco (1944)- y la similitud entre ellas -como Oriente cristiano, Re-unión, Unidad cristiana-.

Hemos de subrayar la ausencia de medios representativos de los húngaros, uno de los grupos más nutridos del exilio. El carácter dinámico de sus componentes de forma individualizada y no grupal explica, entre otros motivos, que se encuentren personalidades de esta nacionalidad en medios de comunicación generalistas, aunque no cuenten con un órgano de expresión propia, a excepción de las emisiones radiofónicas. Es el caso del conocido periodista Andor Révész (SZABÓ, 2004; Olmos, 2002: 383-385; PÉREZ MATEOS, 2002; LóPEZ DE ZuAZO, 1981) o Zoltán Ronái, redactor de publicaciones especializadas de la diáspora húngara ${ }^{2}$. Estos medios se desarrollaron sobre todo entre 1949 y 1969 , fecha en la que se decidió el cese de la mayoría de las cabeceras debido al inicio de relaciones económicas y consulares con los países del COMECON y el acercamiento al Este -la llamada Ostpolitik- propuesto desde Alemania por el canciller Willy Brandt.

${ }^{2}$ Révész comenzó trabajando en el periódico El Sol (1919-1921) y después pasó a la plantilla de $A B C$. En cuanto a Zoltán Rónai, trabajó en colaboraciones para Sorsunk (Nuestro Destino), Kanadai Magyarság, Katolikus Magyarok Vasarnapja o Magyarok Útja, Oriente, Oriente Europeo, Polonia. Revista Ilustrada, Política Internacional, Revista de Estudios Politicos, Arbor, JOC, Cuadernos Hispano-Americanos, Revista Española de Pedagogía, los periódicos Informaciones y $A B C$. Los datos sobre su biografía se han extraído de las entrevistas realizadas en Madrid a su esposa Isabel Medina en octubre-noviembre de 2007. Agradezco a la Sra. de Rònai su amabilidad y generosidad. 


\section{El contexto histórico de la inmigración política centroeuropea}

El marco histórico de dichos medios se sitúa con la llegada a España de los refugiados anticomunistas, vinculada al rechazo de los gobiernos implantados en Europa del Este. A lo largo de la II Guerra Mundial, pero sobre todo, a partir de su final, comenzó un movimiento de exiliados que, desde 1945 a 1989, arrojó fuera de sus territorios al menos a un 5\% de la población de Polonia, Checoslovaquia, Hungría, Rumania y Bulgaria, quienes, en general, se dirigieron a Europa, Estados Unidos o América Latina (Hollian, 2010: 134-161; Wyman, 1989; Marns, 1985; Proudfoot, 1956; VenANT, 1953). Estos países ofrecían buenas perspectivas económicas, posibilidades de actuación política y apoyo gubernamental para sus actividades anticomunistas -especialmente en Estados Unidos-. En el territorio continental, los predilectos serían la República Federal de Alemania, Italia y Francia...., aunque algunos eligieron un país singular en el mapa de la Guerra Fría: España.

A partir de 1946, pues, tuvo lugar la llegada paulatina de exiliados pertenecientes a un abanico social que incluiría desde la aristocracia a pequeños burgueses. Consideraron que España sería un lugar aceptable para fijar su nuevo domicilio basándose en las siguientes razones: la primera, de tipo político, se sustentaba en el grado de afinidad ideológica con el franquismo y su planteamiento de sociedad jerarquizada, disciplinada, "desactivada" para la movilización política. La segunda razón radicaba en las facilidades concedidas por el gobierno a extranjeros de perfil anticomunista y de religión católica en cuanto a la obtención de residencia, lugar de trabajo o estudio y cierta libertad de acción política (TORQUEMADA, 2009). Para el gobierno español la acogida de esta diáspora no transgredía las decisiones del bloque occidental ni diseñaba líneas originales de actuación sino que más bien secundaba las políticas británica y norteamericana, administraciones que se mostraron muy generosas ofreciendo cobijo, apoyos económicos y facilidades para la expresión y la asociación de los exiliados del Telón de Acero.

Entre los nuevos residentes que decidieron asentarse en la España franquista hemos de señalar a húngaros, búlgaros, rumanos, polacos, ucranianos y, en menor medida, checoslovacos. En el decenio 1945-1956 los más numerosos fueron los originarios de Hungría (aproximadamente 425 personas); Rumania y Yugoslavia (110), y Bulgaria (60). Checoslovacos y polacos tuvieron una presencia mínima hasta 1955, fecha en que Polonia comenzó a destacar en el número de residentes 3 . La mayoría se estableció en Barcelona y Madrid, ciudades que ofrecían mayores oportunidades de desarrollo profesional y de bienestar económica (EIROA, 2007: 21-48). En ningún caso constituyeron colonias nutridas como las afincadas en Alemania o Francia, pero desplegaron una gran actividad social, comunicativa y de relaciones públicas en proporción al reducido número de sus integrantes. Algunas nacionalidades como los húngaros, tuvieron menos éxito a la hora de organizar sus propios órganos de expresión, aunque algunos de sus intelectua-

\footnotetext{
${ }^{3}$ Anuario Oficial de Estadística, 1946-1956. Movimiento de Extranjeros en España. Estas cifras no recogen a la totalidad de los exiliados, a veces inscritos sólo en los consulados o en sus representaciones oficiosas. Resulta imposible cuantificar con exactitud su número, aunque pensamos que no sería muy superior a la que marcan las cifras oficiales.
} 
les y periodistas fueron bastante conocidos en diversos círculos sociales como ya hemos mencionado. Búlgaros o checoslovacos se asentaron en núcleos aún más reducidos y tampoco lograron articular instituciones estables que pudieran atraer a los refugiados. Esta situación se debe, en parte, al escaso atractivo que ejercía nuestro país para los que profesaban la religión ortodoxa -caso de los búlgaros-, o sobre exiliados de perfil político claramente democrático -caso de los checoslovacos-.

La admisión de esta diáspora se enmarca en un contexto en el que el Estado español pretendía acercarse a la política de bloques liderada por Estados Unidos y acabar con el aislamiento al que estaba sometido por Naciones Unidas desde 1945. Con este objetivo adoptó un conjunto de medidas entre las que destacaremos, en primer lugar, la apertura de instituciones como el Colegio Mayor Santiago Apóstol y las legaciones diplomáticas oficiosas, a cuyo cargo se hallaban ministros plenipotenciarios con funciones consulares y de relaciones públicas desde 1949. Desde estas legaciones se organizaron de manera semejante a como lo estaban haciendo en Gran Bretaña y Estados Unidos a través del National Comitee for a Free Europe, fundado en 1949 en New York o las representaciones de los gobiernos en el exilio que existían en Londres, París, Roma o Berlín. Asimismo, el gobierno autorizó a finales de 1948 la puesta en marcha del Comité de las Naciones Oprimidas por el Comunismo, formado por antiguos ministros, diplomáticos y representantes oficiosos de Hungría, Eslovaquia, Croacia, Bulgaria, Polonia, Rumania y República Checa. Dicho Comité desarrollaba cierta actividad política, social y propagandística y disponía de su propio boletín informativo como veremos posteriormente ${ }^{4}$.

En segundo lugar, medidas de carácter propagandístico y divulgativo según las cuales el exilio del Telón de Acero dispuso de órganos de expresión para sus fines políticos, mientras que el Estado tuvo la posibilidad de convertirlos en instrumentos bajo su control o en mecanismos de prestación de beneficios para la política exterior. En consecuencia los refugiados desplegaron cierta actividad comunicativa, siendo los rumanos y polacos los más productivos a pesar de que conformaron núcleos minoritarios.

\section{La prensa del exilio polaco: el caso de Polonia. Revista Ilustrada}

Los polacos tuvieron muy claro desde el principio la necesidad de relacionarse con los poderes públicos españoles, una actitud integradora y alentada por la afinidad religiosa del colectivo con el catolicismo predominante en España. Este grupo contaba con una representación diplomática considerada a todos los efectos protocolarios como una legación oficial, hecho que explica las audiencias con Franco y la presencia de los ministros plenipotenciarios Marian Szumlakowski y Josef Potocki en los actos institucionales.

La prensa polaca del exilio surgió en los primeros tiempos del estallido de la Segunda Guerra Mundial y de la ocupación alemana, cuando los huidos y presos en campos de concentración pusieron en marcha revistas y folletos que mantenían cohesionado al grupo y animadas a las tropas que combatían en los campos de bata-

\footnotetext{
${ }^{4}$ Archivo del Ministerio de Asuntos Exteriores (AMAE) Legajo R-4439.1.
} 
lla europeos. Se calcula que en 1940-1941 la producción periodística en el exilio incluía periódicos, boletines, panfletos y hojas en un número creciente hasta llegar a unos 728 títulos distribuidos por 39 países, de los cuales unos 202 fueron publicados en Gran Bretaña, donde se estima que al final de la Guerra Mundial se hallaban instalados unos 95.000 polacos. Después de 1945, con la constitución del gobierno en el exilio, muchas de estas cabeceras desaparecieron y solo sobrevivieron algunas (SEBROWSKI, 2007; JAROSZYNSKA-KIRCHMAN, 2004; SUPRUNIUK, 1995; SwORD, 1989). Poco tiempo después nacieron otras nuevas con fines eminentemente políticos y culturales, como Wiadomosci (Noticias Polacas), Robotnik (El Trabajador, del Partido Socialista Polaco), Trybuna, (del partido MID, Movimiento por la Independencia y la Democracia) o Kultura, (editado en París) ${ }^{5}$.

Las relaciones entre los exiliados no fueron fáciles y, al igual que otros colectivos, reprodujeron en la diáspora los enfrentamientos que les habían dividido en su propia nación. Sin embargo les unía la pertenencia mayoritaria a la religión católica y su idea de defender la independencia de Polonia de cualquier agresión extranjera, ya fuera procedente de la URSS o de Alemania, sus ancestrales enemigos fronterizos. La colonia polaca residente en España, de escaso número hasta 1955 (aproximadamente unos 110) respondía a un perfil social de clase media alta y nobleza, de credo católico y polarizada en torno a sacerdotes de distintas parroquias quienes ejercían sobre ellos mayor influencia que los representantes oficiales M. Szumlakowski y J. Potocki (RoDRÍGUEZ, 1995: 521-546; BANASZEK, 2001: 151-188). Editaron las revistas Nosotros, El comercio exterior de Polonia, El comercio exterior polaco y Polonia. Revista ilustrada, la de mayor duración y difusión (MIELCZAREK, 2003: 125-134).

Polonia. Revista ilustrada, comenzó su andadura en 1955 y pervivió hasta 1969, momento en el que el gobierno de Franco comenzaba a pactar acuerdos económicos con el COMECON, en los que figuró como uno de los requisitos que finalizara la protección a los exiliados polacos. De periodicidad mensual, la empresa editora era la Cruz Roja y su director fue Julio Babecki hasta su muerte en enero de 1966. A partir de entonces se hizo cargo de la dirección interinamente su hijo Luís y posteriormente recayó en Antonio Deryng, presidente de la Asociación de Excombatientes polacos, cambiando el diseño de la revista hacia un estilo más moderno.

Entre sus características técnicas destaca su formato pequeño a modo de un libro, dos columnas y 36 páginas. Este espacio se repartía entre el texto y algunas fotografías e ilustraciones que a veces ocupaban la página entera. La publicidad en los primeros números era mínima, pero con el paso del tiempo se trasladó a las páginas finales y a la contraportada, siendo los anunciantes empresas de productos alimenticios, colegios, moda o instituciones públicas suscriptoras de la revista. Al principio contaba con secciones fijas -"Sobre Polonia", "Noticias breves" y "Humor y polí-

\footnotetext{
${ }^{5}$ Otras cabeceras publicadas por los exiliados en Londres fueron: Biuletyn Gminy Polskie, Zachodniego Londynu CzySyk, Gazetka szkolna, Dziennik Polski, Dziennik śołnierza, Fotorama, Gazeta Niedzielna, Gmina Polska Londyn-Południe, Komunikat, Kronika, Tygodnik dla wszystkich, Nad Tamizą, Nasza Gmina, Orzeł Biały, Polska Walcząca, Rzeczpospolita Polska, Tydzień Polski.
} 
tica"- aunque había textos no encuadrados en secciones que podríamos categorizar en torno a la temática de "Polonia" o "Cultura polaca". A partir de 1965 los contenidos se organizaron en secciones denominadas "De re soviética", "Noticias breves" y "Humor y política", y se intercalaban con artículos sueltos. La mayoría de los artículos aparecían sin firmar o con el nombre de "Corresponsal en...", mientras que otros procedían de la pluma de poetas y escritores muy conocidos residentes en España, como José Lobodowski' (BAK, 2006: 229-241; BAK, 2007: 149-156), o el Conde Potocki, el representante oficioso del gobierno polaco en el exilio.

Los géneros más frecuentes eran los de opinión y en sus páginas se reprodujeron cuentos, ensayos y otro tipo de textos parecidos al reportaje. Se vendía por suscripción y entre los "suscriptores de honor" se encontraban Francisco Franco y sus ministros, el Cardenal Enrique Pla y Deniel, el Nuncio Apostólico, obispos y arzobispos, algunos embajadores, gobernadores civiles, ayuntamientos, aristócratas, empresarios y particulares relacionados con el mundo de la banca, como Emilio Botín.

Los contenidos, categorizados desde un punto de vista cualitativo, trataban de cuatro temas básicos: en primer lugar, Polonia, su cultura, costumbres, monumentos o arte, siempre descritos con un gran idealismo y con un propósito de alimentar el nacionalismo polaco a través de la narración de leyendas o de la exaltación histórica de la patria y de sus hombres. En segundo lugar, la URSS y su sistema político, criticado y ridiculizado con el propósito de demostrar la inviabilidad del sistema y la atrocidad de sus gobernantes. En tercer lugar, el catolicismo, desde su punto de vista la mejor vía para combatir el comunismo y la depravación moral de los pueblos bajo su órbita. Finalmente España, considerada la abanderada de los pueblos en lucha contra el comunismo, líder del catolicismo mundial y puesta como ejemplo para Occidente. En algunas ocasiones se reproducían artículos alusivos a las relaciones históricas hispano-polacas, con un propósito claro de mostrar los paralelismos y la larga amistad entre ambos. Hemos de destacar el hecho de que estaba escrita en castellano, a diferencia de otras publicaciones del exilio instalado en los países occidentales que se publicaban en lengua polaca. Esta decisión se debe, tanto a la voluntad manifiesta de divulgación de sus contenidos entre la sociedad española como al grado de integración del núcleo polaco.

Polonia. Revista ilustrada funcionó para los exiliados como un instrumento de cohesión, un órgano de interacción y comunicación interno que difundió valores nacionalistas y religiosos al tiempo que planteó una crítica constante hacia el poder establecido en Polonia. Igualmente fue un instrumento cultural, un vehículo de difusión de literatura, historia y folklore que actuó a modo de foco para la memoria cultural de la patria polaca con fines abiertamente nacionalistas. Para el gobierno español

${ }^{6}$ Escritor, poeta, y traductor de obras de la literatura española y rusa al polaco. En 1941 intentó pasar clandestinamente por los Pirineos para llegar a Inglaterra, pero fue detenido y conducido a la prisión de Figueras. Liberado en 1943 llegó a Barcelona y desde allí marchó a pie a Madrid donde permaneció el resto de su vida. Trabajó en la sección polaca de Radio Madrid, escribió en el periódico londinense de los exiliados polacos Novedades, y también lo hizo en la revista parisina Kulturze. 
supuso un medio de comunicación minoritario y elitista factible de utilizar en sus relaciones internacionales. Hemos de recordar que el año de su puesta en marcha, 1955, fue el de la incorporación de España a Naciones Unidas, y la diplomacia pudo esgrimir ante otros países que también Madrid contaba con publicaciones de los refugiados al igual que París, Londres o New York. Los polacos, en consecuencia con su carácter profundamente religioso, solían pertenecer a asociaciones católicas internacionales como Pax Romana, y se movían con relativa asiduidad por Europa y Estados Unidos. Este hecho significaba que el gobierno de Franco se beneficiaba de la propaganda que le procuraba la movilidad de los polacos, es decir, de la difusión de un mensaje por Occidente sobre la permisiva y pacífica España en comparación con el sistema comunista de los países del Este. George L. Mark, presidente de la Legión Polaca de los Excombatientes del Ejército norteamericano durante su estancia en Madrid a instancias de la colonia polaca declaró: "De todos los países que he visitado no conozco ninguno tan anticomunista como éste. Me ha interesado mucho cambiar impresiones con las distintas personalidades españolas y así poder contrarrestar a mi regreso a los Estados Unidos cierta propaganda maliciosa que aparece con frecuencia en determinados periódicos de América"7.

\section{La prensa del exilio rumano: Libertatea y Carpatti}

La instalación de exiliados rumanos en ciudades españolas se enmarca en un contexto de huida intensa a partir de la instalación del comunismo entre 1945 y 1948. La nueva ola de evadidos al "mundo libre", se encontró con otros compatriotas que habían escapado de las persecuciones del régimen de Antonescu llevadas a cabo a partir de enero de 1941 (MARINESCU, 1999; DuMITRESCU, 1997).

En la década de 1946-1956 miles de rumanos abandonaron el país para dirigirse a Estados Unidos, Francia, Alemania, Italia y España, donde se organizaron en comités de diverso tipo. Madrid y París recibieron a ex-diplomáticos y políticos, si bien, el exilio legionario superó en número y organización al meramente anticomunista. Junto a ellos existía un grupo importante, tal vez la mayoría, que no estaba encuadrado en ninguno de esos comités. La capital francesa fue el centro de los intentos de agrupación de los exiliados, y los residentes en España desempeñaron un papel muy activo en dicho intento. En 1948 se creó la Unión Demócrata de los Rumanos Libres (con sede en París), que contaba con un Boletín rumano de Informaciones y una emisora de radio, cuyos delegados en Madrid eran George Antoniade y Aron Cotrus, ex consejero de prensa de la Embajada rumana.

En España había representantes de las distintas facciones, aunque la mayoría eran legionarios de la Guardia de Hierro y seguidores de Horia Sima, incluido el ministro oficioso de la Legación Real en Madrid Georges Dimitrescu, jefe del grupo. Los hombres de la Guardia de Hierro fueron protagonistas de numerosos actos políticos y participaron activamente en la organización de los residentes. En 1951 se presentó un proyecto para la creación de una Comunidad de Rumanos cuyo presidente era Dimi-

\footnotetext{
${ }^{7}$ Polonia. Revista ilustrada, no 2, febrero 1955, p. 14.
} 
trescu. Más tarde se integró en esta Comunidad el Círculo Rumano para la Unión Latina, presidido por Aron Cotrus, y existía también la Asociación Rumana Pro-Besarabia y Bucovina. Estos organismos a veces se reunían para celebrar actos conjuntos como la Semana Rumana, celebrada en Madrid en abril de 1953. Con este trasfondo ha de interpretarse la gran actividad cultural que desplegaron debido tanto a la pujanza de los legionarios para divulgar su ideología como a la presencia de personas de alto nivel formativo como Aurel Rauta, autor de la primera gramática rumana para españoles fechada en 1948 y fundador de la Asociación Hispano-Rumana, o el ya mencionado Aron Cotrus.

Las publicaciones rumanas de la década de los cincuenta responden al concepto de la "resistencia a través de la cultura", es decir, la idea de que lo único que se podría hacer era mantenerse fuerte y crítico en el "simbólico monasterio del espíritu" (PETRESCU, 2008), como una forma de expresión de la oposición. Este periodo, pues, destaca por una importante producción periodística e intelectual, entre la que sobresale Libertatea - La libertad -, editada en Madrid, cuyo periodo de máxima actividad tuvo lugar en 1952-1953, o la revista Carpatii -Los Cárpatos- de contenidos culturales.

Libertatea -(1951-1958)- fue un periódico legionario escrito en rumano de periodicidad bimensual. Dirigido por Vasile Iasinschi, entre los miembros de la redacción se hallaban conocidos intelectuales del colectivo exiliado. Técnicamente tenía formato tabloide, con cuatro columnas y seis páginas, sin publicidad y con textos de gran extensión. Las ilustraciones se reducían a la portada y contraportada y a la página tres. Contaba con secciones fijas, "Portada, "Crónica externa", "Rúbrica Berabiei si bucovinei" y "Culturale" y algunas secciones aleatorias completadas con curiosidades. Abundaban los géneros de opinión, a veces agrupados en una sección no fija denominada "Comentarii", aunque en la contraportada se reproducían breves noticias de carácter informativo generalmente sobre las actividades del movimiento legionario en otros países. Igualmente hay referencias a otras publicaciones legionarias o del exilio rumano como Insemnari (Apuntes, editada en Buenos Aires), bajo la dirección de Radu Ghenea, antiguo ministro de Rumania en Madrid, La Nation Roumaine, o el boletín $B I R E$, editados en París.

El análisis cualitativo indica que sus contenidos eran eminentemente religiosos con imágenes de Cristo y referencias a los evangelios- y culturales -se publicaban poemas, narraciones, cuentos y otros textos literarios-, en los que se sublimaba la religión católica y las tradiciones rumanas. Estaba orientado a inocular la idea de que la libertad se conseguía a través de la religión y de la fe y, en consecuencia, todos los sistemas que se hallaban fuera de estos parámetros impedían la libertad de los individuos.

La revista Carpatii. Revista Culturala (1954-1985), escrita igualmente en rumano, tuvo una periodicidad cambiante a lo largo de los años que duró, de orientación legionaria y publicada también en Madrid. En un principio, la dirigía Aron Cotrus y el redactor principal fue Traian Popescu. De formato tabloide a tres columnas y con 16 páginas, no incluía publicidad y sus contenidos estaban organizados en textos largos, combinados de forma moderada por fotografías e ilustraciones pequeñas y de baja calidad. No había una delimitación fija de secciones y los géneros predominantes eran los de opinión -ensayos y columnas- y textos literarios variados, especialmente los po- 
emas o biografias. Con el paso del tiempo se redujo a 12 páginas y se introdujeron secciones fijas escritas en varias lenguas como francés, español, inglés, rumano y alemán.

Con una tirada aproximada de 1000 ejemplares, se explicaba el sentido de la revista en un artículo del número 1 de 10 de mayo de 1954 en el que anunciaba: "se dirige a los exiliados rumanos de España, pero también de Europa, EEUU y Canadá”. Y afirmaba: "Uno de los puntos principales del programa de nuestra revista es el de difundir, entre los rumanos desterrados, escritos literarios cercanos al alma de nuestro pueblo. Se recibe la colaboración de cualquier rumano, pues la revista no pertenece a ningún partido político". La mayor parte de sus contenidos consistían, sin embargo en la propaganda del Movimiento Legionario a través de colaboraciones que permiten realizar la reconstrucción histórica de dicho Movimiento ${ }^{8}$. Las reivindicaciones territoriales de las zonas sesgadas por Hungría, junto a la historia rumana, la literatura, el arte y la crítica al comunismo, fueron otros temas abordados en sus páginas.

El Movimiento Legionario contó desde abril a diciembre de 1957 con un programa en la emisora de Radio Alerta de Falange, que emitía en onda corta. El programa, de 20 minutos diarios, trataba sobre Rumania y participaban en él algunos líderes legionarios residentes en Madrid, como el Comandante Horia Sima y Georges Dimitrescu. Sin embargo el gobierno no vio con buenos ojos la exaltación revolucionaria que se emitía desde sus micrófonos, portadores de noticias que no alentaban la política de coexistencia instalada en esos años entre los bloques de poder y, sobre todo, temeroso de algún posible contagio revolucionario a las huestes de Falange Española, en esos años muy activas contra las primeras protestas habidas en la Universidad española.

Algunos de estos exiliados se convirtieron en "hispanistas rumanos", como consecuencia del origen común de los dos pueblos y la cercanía de los idiomas. H. Sima, por ejemplo, se convirtió en un prolífico autor de textos. Escribió en español y rumano numerosas obras que fueron editadas por Dacia, Fuerza Nueva o El hombre nuevo. En 1963 publicó un artículo sobre "La prensa legionaria en el exilio" en la revista Sentinela en el que hizo un repaso de toda la prensa de esta facción política que apareció hasta 1963 en toda Europa occidental. Otro ejemplo fue George Uscatescu, profesor en las Universidades de Barcelona, y Complutense de Madrid, donde tuvo el cargo de Director del Departamento de Estética y Arte. Publicó más de cien volúmenes y decenas de estudios y artículos en Europa y en Estados Unidos sobre filosofía,

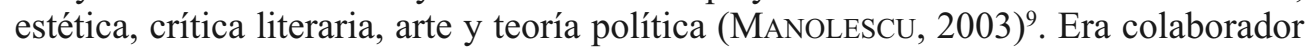
fijo de la sección rumana de la revista Oriente Europeo. Un exiliado importante fue también Vintila Horia, instalado en Madrid en 1953, integrante del grupo literario que trabajaba para la revista Vremea (El Tiempo), Catedrático de Literatura Comparada en la Universidad Complutense, fundador de la colección del libro de bolsillo "Punto

\footnotetext{
${ }^{8}$ El redactor Traian Popescu, dedicó varios números monográficos al Movimiento Legionario, como el de 1958 y 1962. En el número 2-3 de 10 de mayo-10 de julio se realizó un dossier completo rememorando los 25 años del frente de Majadahonda de la Guerra Civil española.

${ }^{9}$ Fue presidente de la Sociedad Íbero-Americana y recibió el Premio Nacional de Literatura Menéndez Pelayo en 1970. Entre sus obras más conocidas se encuentra Rumania, pueblo historia, cultura, Editorial Madrid, 1955.
} 
Omega", colaborador del periódico ABC, Semana, El Alcázar, Cuadernos HispanoAmericanos, así como de otros medios editados en Francia e Italia. Obtuvo el Premio Goncourt en 1960 con su obra Dios ha nacido en el exilio, pero renunció a él por la campaña desatada en Francia debido a los poemas antisemitas escritos en su juventud. El ambiente intelectual de la década de 1960 no podía aceptar sospechas de un pasado comprometido con los países nazi-fascistas de los años de II Guerra Mundial.

En España, pues, estos exiliados tuvieron una producción informativa intensa, dirigida a un público objetivo muy concreto, enmarcada en un contexto de gran permisividad hacia los contenidos, y con funciones de cohesión social, de exaltación patriótica y de propaganda anticomunista.

\section{Los medios oficiales para combatir el comunismo internacional: Radio Nacio- nal de España y la prensa especializada}

En este marco de asentamiento de refugiados procedente de las democracias populares, el gobierno español decidió la puesta en marcha de iniciativas mediáticas que apoyaran sus actuaciones y políticas. Una de éstas fue la emisión de programas en lenguas extranjeras en Radio Nacional de España a partir de 1949. Sus objetivos eran similares a los de Radio Free Europe -fundada por el Congreso de los Estados Unidos y el National Comitee for a Free Europe en 1949- o Radio Liberty (PUDDINGTON, 2003), cuya creación formaba parte de una estrategia de la Central de Inteligencia Americana (CIA) en la que se contemplaba la posibilidad de hacer propaganda contra el Telón de Acero a través de las ondas (CULL, 2008; PARTA, 2007; NúÑEZ, 1980).

La financiación de las emisiones de $R N E$ dependía del Estado aunque su coste fue muy reducido teniendo en cuenta que se utilizaban los recursos materiales y técnicos de la radio estatal. A tenor de la exigua información que ofrecen las fuentes parece que algunas de estas emisiones, la polaca por ejemplo, recibía dinero de los refugiados en Canadá así como de la hacienda nacional del gobierno polaco en el exilio y de Estados Unidos ${ }^{10}$.

La propuesta de ponerlas en marcha partió de Otto de Habsburgo, el heredero a la corona húngara exiliado en España, en el transcurso de una reunión con Franco. Otto planteó esta medida como una vía eficaz y de largo alcance para el combate contra el comunismo en una coyuntura inicial de la Guerra Fría coincidente con el final del aislamiento internacional del franquismo. Santiago Morillo manifestó que surgieron a iniciativa de Franco con el propósito de "trasladar el frente de batalla a las mismas madrigueras del comunismo y a los países por él esclavizado, contribuyendo con ello a la liberación de la Europa subyugada"11. Al impulso de esta idea nació la primera emisión en lengua rusa a la que después le siguieron la húngara, polaca, rumana, eslovaca, ucraniana, lituana, checa, croata e incluso la china, en esa difícil empresa de "estrechar el cerco de la hidra con emisiones en todas las lenguas de los países atenazados

\footnotetext{
${ }^{10}$ Archivo General de la Administración (AGA). Emisiones en onda corta: extranjeros. Sección 49.3. En el archivo de Radio Nacional de España no se ha conservado la grabación de los programas.

${ }^{11}$ Polonia. Revista Ilustrada, no 2, p. 23, febrero 1955.
} 
por el comunismo". Estas emisiones, pues, tenían como objetivo llegar hasta el interior de los países del Este e incitar a la sublevación interna contra los gobiernos.

Al menos en los primeros años de su funcionamiento sabemos que su duración se estableció entre media hora y quince minutos diarios y consistían en un espacio con noticias de actualidad internacional, especialmente dedicada a los países comunistas, música folklórica y noticias de carácter cultural y nacionalista. En sus ondas recordaban las fiestas patrióticas de sus respectivas naciones, sus tradiciones, criticaron duramente al comunismo y la persecución religiosa y alabaron profusamente a la España de Franco. Los menguados recursos con los que se producían los programas fueron compensados con el entusiasmo que los redactores mostraron, según se infiere de su propio testimonio y de referencias indirectas ${ }^{12}$. Los redactores y locutores de las emisiones eran prácticamente los mismos que los que participaban en otros medios de la diáspora: José Lobodowski, Casimier Tylko, Zoltán Ronai, Francis Chajma... No eran periodistas sino intelectuales ó antiguos colegiales del Colegio Mayor Santiago Apóstol residentes en España que desde 1946 trabajaban como traductores, profesores, escritores o periodistas. Formaban un círculo muy estrecho que manejaba toda la información y la propaganda dirigida a los refugiados de las democracias populares.

No disponemos de datos cuantificadores sobre la audiencia de estas emisiones aunque contamos con muestras indirectas de su recepción. En primer lugar, cartas y despachos enviados por autoridades exiliadas a Franco o al Ministerio de Asuntos Exteriores en los que informaban sobre su recepción y la amplia acogida entre la población polaca exiliada y también del interior del país que la oía de forma clandestina. Entre otros destacaremos la carta que dirigió el General Wladislaw Anders, jefe del gobierno polaco en el exilio en Londres, al Ministerio de Asuntos Exteriores el 10 de marzo de 1949 en la que agradecía la iniciativa y señalaba el gran apoyo que esta emisora suponía para los polacos y su lucha por la independencia. Un año después, en enero de 1950, el ministro oficioso de Polonia en España, conde de Potocki, informó al ministro Alberto Martín Artajo que se calculaba en unos 100.000 los compatriotas que oían las emisiones en polaco aunque estas cifras no se han podido confirmar. Una prueba relativa de su eficacia es el agradecimiento enviado por el Comité de las Naciones Oprimidas por el Comunismo en España a Franco, en el que aplaudían la decisión de organizar programas de estas características, teniendo en cuenta la gran importancia que éstos podían adquirir en la lucha contra los gobiernos y el apoyo a la oposición en el interior.

Un indicador más del relativo éxito de Radio Madrid, como se la conocía en Polonia, es la opinión de la Comisión de Europa Central y Oriental del Movimiento Europeo, relativa a que conocían la acogida de las emisiones entre los exiliados y en el interior de los Estados del Telón de Acero. La Comisión afirmó que, algunas de estas peculiares emisoras nacidas en el contexto de la Guerra Fría, llegaron a tener numerosos seguidores, aunque los estudios de audiencias de radios similares parecen indicar que el número de radio-oyentes era muy reducido. Podríamos añadir, además, la

${ }^{12}$ Entrevistas a Francis Chajma, Casimir Tylko y Zoltan Ronai en 2003. 
queja de las autoridades comunistas contra la programación de estas radios, especialmente la $B B C$ y Radio Free Europe. Sabemos que existía un departamento del Partido Comunista polaco que escuchaba y transcribía lo emitido a modo de espionaje de los contenidos. De hecho el gobierno polaco admitió en 1957 que las emisoras extranjeras tenían cierta influencia en la opinión pública y que Radio Madrid era bastante oída. La razón primordial es que no tenía censura oficial ni compromiso con Occidente, así es que se permitía la licencia de criticar a cualquier país, incluida Alemania, uno de los enemigos de Polonia.

El Régimen de Franco, distinguido por el fuerte intervencionismo sobre los medios, no puso trabas censoras a estas emisiones, seguro de que sus contenidos se ajustaban a las directrices ideológicas y formales diseñadas desde el Estado. Otras radios como Voice of America o Radio Free Europe, ofrecían una valiosa información pero no eran tan libres de opinar sobre sus aliados. En consecuencia los oyentes escuchaban sus ondas, porque su programación era variada - programas culturales, de entretenimiento, musicales, etc.,- y de orientación democrática, pero también conectaban con Radio Madrid al considerar que su opinión estaba menos mediatizada porque su gobierno no estaba sujeto a tantos compromisos internacionales. A diferencia de las emisiones británicas, más partidarias de la política de apaciguamiento y distensión que se inauguró en el sistema bipolar tras la muerte de Stalin, la voz española difundió la consigna de una guerra decidida y sin cuartel contra el comunismo y se erigió en "voz resistente" de los pueblos oprimidos. La curva del anticomunismo crecía constantemente alimentada como consecuencia de la Guerra de Corea, el nacimiento de la República Popular China bajo las órdenes de Mao, la invasión soviética de Hungría en 1956 o el triunfo de Fidel Casto en Cuba. En este contexto la radio española se posicionaba como uno de los pilotos más radicales en la batalla contra el comunismo que parecía extenderse a lo largo del planeta.

Además de la radio existían medios escritos que el Estado promovió para el conjunto de la diáspora anticomunista, como el Boletín Informativo de las Naciones Oprimidas por el Comunismo, editado por el Comité de las Naciones Oprimidas por el Comunismo con periodicidad mensual. Su primer número es de junio de 1949, coincidente con la puesta en marcha de las emisiones de $R N E$, e incluía artículos de cada uno de los países miembros del Comité, es decir, Bulgaria, Croacia, Eslovaquia, Hungría, Polonia, Rumania y, algún tiempo después, la República Checa. Constaba de 16 páginas a cuatro columnas sin ilustraciones ni fotografías ni publicidad y sus hojas de formato periódico estaban grapadas. Se hacía con recursos económicos mínimos y se vendía por suscripción, aunque no constaba la tirada ni el listado de suscriptores. Todo indica que se repartía en las instituciones oficiales y algunos centros de socialización de la diáspora como las legaciones diplomáticas oficiosas. Esta edición finalizó en 1953 cuando cambió de nombre al de Europa oprimida.

En los artículos de opinión se explicaban las medidas que los gobiernos comunistas estaban tomando sobre el ejército, la industrialización, la población o los credos religiosos, especialmente el católico. En ellos se ofrecía una visión de la política comunista y de sus resultados negativos en todos los sectores y se invitaba a combatirlo desde acciones individuales o colectivas. Consideramos que tuvo una influencia casi 
nula entre el conjunto de los residentes exiliados porque se concibió como un órgano informativo de distribución restringida cuya función fue la de agrupar en una sola publicación la información sobre el Telón de Acero para una visualización sintetizada de los acontecimientos. De ahí el mantenimiento de un formato peculiar de boletín interno de comunicación.

El Centro de Estudios Orientales (CEOR), dirigido por el padre Santiago Morillo, era el editor de dos publicaciones, Oriente, revista trimestral y Oriente cristiano, semanario encargado de difundir la idea de unión de las Iglesias. A partir de 1956 se reestructuraron en tres, fruto de la división de Oriente en dos: Re-unión, dedicado a la unión de las iglesias cristianas, problemas teológicos y ecumenistas, y el nuevo Oriente europeo. Esta última tuvo como finalidad: "Ocuparse del más agudo problema moral de nuestros tiempos, la destrucción de la estructura humana por la opresión militar e ideológico-política del sovietismo en más de la mitad de Europa [...]. Oriente Europeo no será una publicación más de lucha política, reducida a los argumentos del realismo corriente. Su base es el realismo cristiano, que no es del poder discrecional, sino del poder del hombre en su libertad, revelada por Cristo, al servicio de lo divino y humano y no para su explotación. Por eso, hoy son los oprimidos el centro del mundo"13.

La revista Oriente Europeo (1956-1972), pues, era continuadora de Oriente (1951$1955)$ y tenía carácter trimestral. Su director, el ya mencionado sacerdote S. Morillo, ejercía numerosos cargos de responsabilidad relacionados con la emigración anticomunista como vice-conciliario general de la Organización Católica Universitaria (OCAU), capellán del Colegio Mayor Santiago Apóstol -residencia de los jóvenes procedentes del Telón de Acero-, y director del Boletín Informativo de las Naciones Oprimidas por el Comunismo. Le acompañaban en su gestión un consejo de redacción integrado por una representación nacional de los exiliados. Sus particularidades técnicas la convertían en una revista tipo libreto o libro, de papel grueso con unas 100 páginas estructuradas en dos columnas para la sección de "Crónicas" y el resto escritas como un texto literario. El espacio estaba cubierto en su totalidad con texto sin ilustraciones ni publicidad y se vendía por suscripción. Las secciones fijas en las que se estructuraba eran cuatro, "Estudios", "Crónica", "Documentos" y "Bibliografía" y recogían artículos de opinión. Contaba con redactores fijos y colaboradores exiliados que escribían sobre temas de la actualidad en el mundo comunista. Algunos eran los representantes de las legaciones oficiosas existentes en Madrid, como Marian Szumlakowski (polaco), Francisco de Marossy (húngaro) o José Cieker (eslovaco), además de otros intelectuales refugiados como Georges Uscatescu (rumano), el poeta polaco Josef Lobodowski o el psicólogo ucraniano Bohdan Cymbalistyj. Desde el número 25, la revista incluía un monográfico sobre países en el que se reproducían noticias sobre distintos aspectos de la economía, la sociedad, la política o la cultura. El número 26 de 1957, por ejemplo, se dedicó a Ucrania ó el 27 a Hungría con motivo de la revolución de 1956. La orientación de los contenidos, en consecuencia con la identidad de

${ }^{13}$ Oriente Europeo, 1956, enero-marzo, no 21. 
la revista, era marcadamente anticomunista y se expresaba a través de la visión multinacional y multidisciplinar que ofrecía su consejo de redacción.

El problema básico de estas publicaciones era el de su financiación y la escasez de las tiradas, reducidas a unos cientos de ejemplares que se vendían por suscripción a organismos políticos y religiosos, instituciones oficiales y a los propios exiliados. En consecuencia, se distribuían entre un público objetivo muy reducido, interesado por el desarrollo político de los países bajo la órbita comunista, pero apenas tuvieron alcance fuera de estos círculos. Funcionaron como un mecanismo de percepción del mundo, esto es, de la realidad exterior al propio exiliado a quien proporcionó una determinada construcción de los significados y valores de los acontecimientos que se sucedían en los países del Pacto de Varsovia. Igualmente, suministraron información que satisfizo su necesidad de conocimiento, aunque éste fuera sesgado y mediatizado por el contexto jurídico e ideológico del centro emisor. Pero también actuaron como agentes promotores de la cohesión social y la interacción de los exiliados, a quienes surtieron de noticias que animaban a la oposición firme y conjunta del colectivo multinacional en el exilio contra los gobiernos comunistas. Asimismo, estos medios sirvieron de propaganda y de instrumento político hacia la compleja política exterior de los gobiernos de la época. Después de que España firmó los Pactos con Estados Unidos en 1953 y fuera admitida en Naciones Unidas en 1955, el ministro Alberto Martín Artajo instrumentalizó las medidas puestas en marcha a favor de los exiliados políticos entre las que se encontraban los medios de comunicación que hemos señalado. El Ministerio de Asuntos Exteriores y Presidencia del Gobierno estimaron conveniente la autorización de este tipo de publicaciones como un aval de la tolerancia informativa y de la posible homologación a otras democracias. Teniendo en cuenta que existían en Francia -Kultura, Sorsunk-, en Gran Bretaña -Wiadomosci, Gazeta Niedzielna, Orzel Bialy- o en Italia -Polonia sacra, La Vita católica in Polonia-, el gobierno pensó que podía esgrimir un argumento de libertad informativa con estas publicaciones. Precisamente este aspecto de la ausencia de libertad de expresión estuvo presente en las negociaciones que se vinieron gestionando con Estados Unidos desde 1950 y constituyó uno de los puntos negativos en el balance que los mediadores norteamericanos realizaron sobre España ${ }^{14}$.

\section{Conclusiones}

Los medios de comunicación editados por los exiliados o por las autoridades españolas responden a una producción informativa de perfil austero, minoritario, de baja tirada y reducida difusión. Este perfil se halla en estrecha relación con el de sus responsables, un colectivo exiguo de exiliados comparado con otros colectivos de extranjeros residentes en España -británicos y alemanes, por ejemplo-, y aún más exi-

${ }^{14}$ Documento 4143 entrevista con D. Eisenhower de 22 de diciembre 1959, Fundación Nacional Francisco Franco. La cuestión sobre la libertad informativa y de credos continuó siempre presente en las negociaciones con Estados Unidos, véase en las conversaciones que Franco mantuvo con Dean Rusk, Secretario de Estado en la administración Kennedy realizada en 1961, en Legajo R-12039.10. AMAE. 
guo si se coteja con las cifras de los que eligieron como destino Europa o Norteamérica. Los contenidos que se divulgaron en sus páginas o a través de las ondas tienen también una correlación con la ideología de esta emigración política, en su mayoría vinculada a sectores de la derecha más conservadora de sus respectivas naciones ó incluso de la ultraderecha, como los Legionarios de la Guardia de Hierro rumana. Esta característica es muy representativa de la prensa producida en España, anclada en la etapa de contención, frente a la editada en Londres o París, más conciliadora con la fase del deshielo y la distensión iniciada desde la muerte de Stalin en 1953 y definitivamente implantada tras la crisis de los misiles de 1961.

Desde nuestro punto de vista, las funciones más importantes que los medios desempeñaron entre los exiliados fueron la cohesión del grupo, la interacción y la instrumentación cultural, mientras que para el régimen franquista supusieron un canal de propaganda y un instrumento político. Sin embargo, estos medios tuvieron una influencia limitada sobre el conjunto exiliado. En primer lugar porque no llegaba a todos, sino a los más activos y vinculados a los círculos de socialización que se establecieron con el apoyo del Estado. Los testimonios orales nos confirman que había muchos que coincidían con sus compatriotas en la celebración del día de la patria o en actos culturales, pero apenas si asistían a los eventos convocados por las legaciones diplomáticas oficiosas o por los antiguos colegiales del Colegio Mayor Santiago Apóstol, centro que tuvo un gran protagonismo en la organización de actos. En segundo lugar porque los mensajes transmitían un pensamiento que una gran parte de los refugiados ya había adquirido desde la salida de sus respectivas naciones, como el culto a la patria, la consideración de una cultura nacional superior a otras, la fe profunda en la religión católica y el combate abierto contra el comunismo.

El sistema informativo franquista acogió bien estas cabeceras porque no alteraba sus principios económicos ni ideológicos. No hacían competencia a ninguna de sus revistas sindicales, culturales o políticas, sino que venían a complementar el abanico de publicaciones permitidas y a cubrir el terreno de la propaganda. Tanto los programas de radio como las publicaciones de los refugiados cumplían esa misión de "servicio" que se había asignado a los medios de comunicación desde 1938. En este caso su "servicio" consistía en reforzar los contenidos de la prensa gubernamental en contra del comunismo y en defensa a ultranza del régimen implantado en 1939. Desde los inicios, la política exterior las instrumentalizó con el propósito de demostrar la indulgencia practicada con el derecho a la libertad de expresión y opinión, siempre y cuando se respetaran las bases doctrinales del franquismo. En el Ministerio de Asuntos Exteriores y en el recién creado Ministerio de Información y Turismo (1951) tenían constancia de que estas publicaciones no eran un hecho aislado en el panorama internacional y entendieron que se podían homologar a las existentes en los países democráticos.

Esta singular producción informativa tuvo un perfil político dominante acompañado de un perfil cultural. A partir de 1969, sin embargo, nos encontramos con publicaciones de signo contrario, es decir, una comunicación institucional de los gobiernos comunistas divulgada en el tardofranquismo. En este año el gobierno decidió la interrupción de las emisiones de $R N E$, el cese de las publicaciones de los exiliados del Pacto de Varsovia, la clausura de las legaciones diplomáticas oficiosas y el cierre del 
Colegio Mayor Santiago Apóstol. Con estas medidas se liquidaban todos los centros de socialización y de colaboración con la emigración anticomunista puesto que se había abierto un camino hacia el respeto y el entendimiento con el bloque del COMECON. En el trasfondo estaban los intereses económicos de una España que no había sido admitida en las Comunidades Europeas y que necesitaba de mercados en los que adquirir y vender productos competitivos a bajo coste. En estas circunstancias, la Europa comunista tuvo la oportunidad de paliar la propaganda enemiga con propaganda institucional y así fue cómo llegaron a España anuarios y revistas ilustradas que formaban parte de una gran estrategia comunicativa para difundir la buena imagen del sistema comunista. La distribución de estos nuevos medios coincidía en el tiempo con la instalación de representaciones comerciales y consulares comunistas oficiales en Madrid, cuya consecuencia fue la aceleración del intercambio de mercancías con la Europa del Este y la apertura de un camino hacia el diálogo que culminaría en 1977 con el reconocimiento oficial de los gobiernos respectivos.

En suma, un panorama informativo multinacional muy complejo pero bien orquestado, representativo de la variopinta sociedad de posguerra y del acontecer internacional de la Guerra Fría. En España, anfitriones y huéspedes buscaban beneficios a corto plazo en un contexto mundial cambiante, en el que era importante encontrar sustentos firmes para lograr la supervivencia en la inquietante división bipolar. El gobierno aprovechó los intereses de los refugiados y su producción mediática para expresar la tolerancia hacia otras nacionalidades ajenas a su cultura y tradición, aunque la procedencia geográfica nunca fue un problema para las autoridades españolas, sino la ideología democrática de sus portadores.

\section{Referencias bibliográficas}

BAK, Gregorz (2007): "Por nuestra libertad y la vuestra. Polonia sigue luchando (1945) de Józef Lobodowski”, Estudios Hispánicos, XV, Homenaje a Piotr Sawicki, Wroclaw.

BAK, Gregorz (2006): "Civilización y cultura. Aproximación a una bibliografía de Józef Lobodwoski", Eslavística Complutense, n 6. Madrid, Servicio de Publicaciones de la Universidad Copmplutense.

BANASZEK, Anna (2001): "Polonia hiszpańska. Charakterystyka historycznospołeczna", Studia Polonijne, $\mathrm{n}^{\circ} 22$.

BARRERA, Carlos (1995): Periodismo y franquismo. De la censura a la apertura. Barcelona, Ediciones Internacionales Universitarias.

BERGANZA, Ma Rosa, y RUIZ SAN ROMÁN, José Antonio (coord., 2005): Investigar en Comunicación. Madrid, MacGraw-Hill.

BLAU, Judith (1998): "Immigrant communities and their newspapers in America, 1850-1930", en Sociological Analysis, nº 1.

CHULIÁ, Elisa (1997): La evolución silenciosa de las dictaduras. El régimen de Franco ante la prensa y el periodismo. Madrid, Instituto Juan March de Estudios e Investigaciones. 
CULL, Nicholas J. (2008): The Cold War and the United States Information Agency. American Propaganda and Public Diplomacy, 1945-1989. New York, Cambridge University Press, New York.

DUMITRESCU, Vasile y FRUNZÂ, Victor (1997): O istorie a exilului romanesc: 1944-1989. Bucarest, Universidad de Bucarest.

EIROA, Matilde (2007): "España, refugio para los aliados del Eje y destino de anticomunistas (1939-1956)", en Ayer, n ${ }^{\circ}$ 67, dossier de EIROA, Matilde y FERRERO, $\mathrm{M}^{\mathrm{a}}$ Dolores (eds): Las relaciones de España con Europa Centro-Oriental (19391975). Madrid, Marcial Pons y Asociación de Historia Contemporánea.

GARCÍA GALINDO, Juan Antonio (2002): La comunicación social durante el franquismo. Málaga, CEDMA.

GARCÍA GALINDO, Juan Antonio (1998): "El papel de los medios de comunicación en la configuración y promoción de la Costa del Sol", en VV.AA., Historia de La Costa del Sol. Diario Sur, Málaga.

JAROSZYNSKA-KIRCHMAN, Anna D. (2004): The exile mision: the polish diaspora and polish americans, 1939-1956. New York, Atheny.

JENSEN, K. Bernard, y JANKOWSKI, N.W., (eds.), (1993): Metodologias cualitativas de investigación en comunicación de masas. Barcelona, Bosch.

LACROIX, Jean Michael (1998): Anatomie de la presse ethnique au Canada. Bordeaux, Prensa Universitaria.

LÓPEZ DE ZUAZO, Antonio (1981): Catálogo de periodistas españoles del siglo $X X$. Madrid, Pirámide.

LÓPEZ ROMERO, Laura (2009a): Prensa y comunidad extranjera en España. Estudio descriptivo y analítico del caso malagueño, Madrid, Quiasmo Editorial.

LÓPEZ ROMERO, Laura (2009b): "Prensa extranjera en España. La integración social a través de los medios escritos", en Telos, julio-septiembre, $\mathrm{n}^{\circ} 80$.

MANOLESCU, Florin (2003): Enciclopedia exilului literar românesc, 1945-1989. Scriitori, reviste, instituții, organizații. Bucarest, Editura Compania.

MARINESCU, Aurel Sergio, (1999): O contributie la istoria exilului românesc. Bucarest, Universidad de Bucarest.

MARNS, Michael R. (1985): The unwanted. European refugees in the $20^{\text {th }}$ century, New York, Oxford University Press.

MARTINEZ NICOLÁS, Manuel y otros; (2008): Para investigar la comunicación. Propuestas teórico-metodológicas. Madrid, Tecnos.

MIELCZAREK, A. (2003): "Información y propaganda en Polonia. Revista Ilustrada, (1955-1969), publicación periódica de la colonia polaca en España”, en Estudios Hispánicos, XI, Wroclaw.

OLMOS, Víctor (2002): Historia del ABC. Madrid, Plaza y Janés. 
PARTA, Eugene, (2007): Discovering the hidden listener: an assessment of Radio Liberty and Western Broadcasting to the USSR during the Cold War. Palo Alto, California, Hoover Press.

PÉREZ MATEOS, Juan Antonio (2002): ABC. Cien años de "un vicio nacional". Historia íntima de un diario. Madrid, Libro Hobby.

PETRESCU, Cristina (2008): "Eastern Europe, Central Europe or Europe? A comparative analysis of Central European Dissent and Romanian "resistance through culture", en FARALDO, José Mª; GULIŃSKA-JURGIEL, Paulina y DOMNITZ, Christian: Europa im Ostblock. Vorstellungen und Diskurse (1945-1991). Köln, Böhlau.

PROUDFOOT, Malcolm J. (1956): European refugees: 1939-1952. A study in forced population movement. London, Faber and Faber Ltd.

PUDDINGTON, Arch (2003): Broadcasting Freedom: The Cold War Triumph of Radio Free Europe and Radio Liberty. Lexington, The University Press of Kentucky.

RIGONI, Isabelle (2007): "Los medios de comunicación de minorías étnicas", en $2^{\circ}$ Anuario de la Comunicación del Inmigrante en España 07/08. Madrid, Etnia Comunicación.

RODRIGUEZ, Vicente (1995): "Los polacos en España: de refugiados a inmigrantes", en Estudios Geográficos, Tomo LVI, n 220, septiembre.

SALVÀ TOMÁS, Père A. (2002): "Prensa y cambios sociales en las Islas Baleares en los años sesenta", en GARCÍA GALINDO, Juan Antonio. y otros (eds.): La comunicación social durante el franquismo. Málaga, Diputación de Málaga, pp. 485493.

SEBROWSKI, Michael (2007): Dzieje sporu. "Kultura" w emigracyjnej debacie politycznej lat 1947-56. Warsaw, Dzieje.

SUPRUNIUK, Miroslaw Adam (ed.) (1995-1996): Wiadomości i okolice. Szkice i wspomnienia. Toruń, 2 vols.

SWORD, Keith; DAVIES, Norman y CIECHANOWSKI, Jan (1989): The formation of the polish community in Great Britain, 1939-1950. London, School of Slavonic and East European Studies.

SZABÓ, Eva (2004): Andrés Révész, el escritor. Szeged, Universidad de Szeged.

TORQUEMADA SÁNCHEZ, M José (2009): La inmigración en España durante las primeras etapas del franquismo, Madrid, Dykinson.

WYMAN, Mark (1989): Europe's displaced persons, 1945-1951. London and Toronto, Associated University Press. 